\title{
Em deslocamento: possíveis trânsitos entre a escrita de um diário de pesquisa e os diários de campo etnográficos
}

En desplazamiento: tránsitos posibles entre la escritura de un diario de investigación y los diarios de campo etnográficos

In displacement: possible transits between writing a journal of research and the ethnographic field journal

\author{
Aline Nunes \\ ameline.nr@gmail.com \\ Programa de Pós- Graduação em Arte e Cultura Visual - Universidade Federal de Goiás/ \\ UFG
}

\section{RESUMO}

O artigo em questão concentra-se na elaboração de um possível diálogo entre a escrita de meu diário de pesquisa e a escrita dos diários de campo por parte dos antropólogos, durante suas imersões etnográficas. Neste sentido discorro sobre aspectos que motivaram a produção deste diário, construído durante o primeiro ano letivo no Programa de Pós-Graduação em Arte e Cultura Visual (PPGACV/ FAV/UFG), e sua relevância no contexto de minha pesquisa doutoral, articulando relações com o tema que a orienta: os deslocamentos territoriais. A tessitura teórica é realizada, sobretudo, a partir de Deleuze (1988), para problematizar os deslocamentos; Eckert e Rocha (2008), Clifford (1991) e Silva (2005) no tocante à escrita etnográfica, dentre outros que compõem os diálogos do texto.

Palavras-chave: diário de pesquisa; diário de campo etnográfico; deslocamentos territoriais

\section{RESUMEN}

El artículo se centra en el desarollo de un possible diálogo entre la escritura de mi diario de investigación e los diarios de campo escritos por los antropólogos durante sus inmersiones etnográficas. En este sentido, describo acerca de los aspectos que motivaron la producción deste diario, que fué construído en el primer año de classes en el Programa de Pós-Graduação em Arte e Cultura Visual (PPGACV/UFG), y su relevancia en el contexto de mi investigación doctoral, cordinando relaciones con el tema que la guia: los desplazamientos territoriales. El tejido teórico se hace principalmente con Deleuze (1988), para discutir los desplazamientos; Eckert y Rocha (2008); Clifford (1991) y Silva (2005) en relación con la escritura etnográfica, entre otros que componen el diálogo en el texto.

Palavras-clabe: diario de investigación; diario de campo etnográfico; desplazamientos territoriales. 


\section{ABSTRACT}

The article focuses on the development of a possible dialogue between my research journal and thefield diaries written byanthropologists during their ethnographic immersions. In this sense writing about the aspects that motivated the production of this journal, built during the first year in Programa de Pós Graduação em Arte e Cultura Visual, of Universidade Federal de Goiás (PPGACV / FAV / UFG) and its relevance in the context of my doctoral research, within its thematic axis: territorial displacements. The theoretical background of the research is based mainly in Deleuze (1988) questions about displacements; Eckert and Rocha (2008), Clifford (1991) and Silva (2005) in terms of ethnographic writing, among other dialogues that make up the text.

Keywords: journal of research; field journal ethnographic; territorial displacements 


\section{À GUISA DE INTRODUÇÃO... OU ABRINDO O MAPA}

Para Deleuze (1988: 04) “não há território sem um vetor de saída do território e não há saída do território, ou seja, desterritorialização, sem, ao mesmo tempo, um esforço para se reterritorializar em outra parte". Sendo assim, é deste movimento de sair do território e desterritorializar-me e, sobretudo, acerca do esforço de territorializar-me em outro lugar, a respeito do qual falarei neste artigo.

Atualmente a pesquisa doutoral que desenvolvo ${ }^{1}$ tem como um de seus eixos refletir sobre os agenciamentos promovidos pelos deslocamentos territoriais experienciados por professores de artes visuais, como possibilidade de também refletir acerca dos trânsitos geográficos pelos quais passei e venho passando, e que, por sua vez, acabam interferindo de modo muito particular e determinante em minha construção enquanto professora e pesquisadora. Tal deslocamento exige de mim um olhar diferenciado sobre o que vejo, mudanças de perspectivas e ainda, constantes negociações.

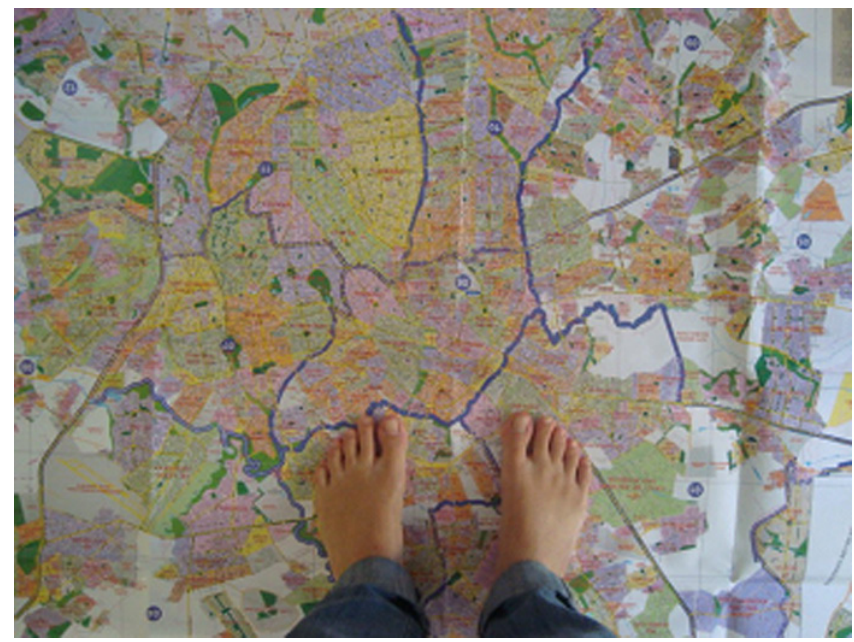

Imagem 1: arquivo pessoal

Neste sentido creio que a etnografia, um dos temas abordados no decurso da disciplina intitulada Seminário Avançado de Pesquisa em Arte e Cultura Visual² (PPGACV/UFG), ajuda

\footnotetext{
1 Pesquisa realizada no Programa de Pós Graduação em Arte e Cultura Visual, da Universidade Federal de Goiás, sob orientação da professora Dra. Alice Fátima Martins. A pesquisa conta com financiamento integral da agência de fomento CAPES.
}

2 As questões trazidas neste artigo partem da escrita elaborada durante a referida disciplina, ministrada pela professora Dra. Rosana Horio Monteiro, realizada no segundo semestre de 2011. -me a levantar reflexões e problematizar este processo de estar em deslocamento e, sobretudo de observar, adentrar e (re)conhecer o eixo investigado. Para tanto buscarei estabelecer relações entre alguns aspectos que me foram significativos no decorrer da referida disciplina, especialmente no que diz respeito a certos apontamentos condizentes a esta abordagem metodológica.

Utilizo-me de alguns textos estudados nas aulas, tais como os escritos de Clifford (1991) em "Introdución: Verdades parciales", as considerações de Cornélia Eckert e Ana Luíza Carvalho da Rocha (2008) em "Etnografia: saberes e práticas", e ainda o texto "Entre a poesia e o Raio X: uma introdução à tendência pós-moderna na antropologia", de Vagner Gonçalves da Silva (2005) que traz um interessante panorama da produção etnográfica contemporânea. Estabeleço articulações com estes textos uma vez que todos eles problematizam a importância da escrita etnográfica, da imersão do pesquisador no campo investigado e da produção dos diários resultantes desta imersão. Não obstante, tecem ainda reflexões acerca da preponderância exercida pelo deslocamento do próprio sujeito enquanto etnógrafo, trazendo importantes elementos para entender e refletir a respeito da pesquisa que desenvolvo neste momento.

Assim para iniciar as problematizações do presente artigo, inicio-o propondo interlocuções entre as concepções de deslocamento com as quais venho operando em minha pesquisa (elaboradas a partir do diálogo com o conceito de desterritorialização, proposto por Deleuze e Guattari (1980)), juntamente a certos aspectos concernentes à etnografia, explicitando minhas relações com tal temática.

\section{PARA ENTRECRUZAR ALGUNS PONTOS DO MAPA}

Na dissertação intitulada "Narrativas Fílmicas e Educação das Artes Visuais - percursos, afetos e bricolagens na formação inicial do professor" ${ }^{3}$, um dos capítulos chamou-se “Uma viagem não é apenas uma viagem, é um reconhecimento". Hoje, no doutorado, tenho ampliado esta questão

\footnotetext{
3 Dissertação produzida no Programa de Pós Graduação em Educação/ PPGE da Universidade Federal de Santa Maria/UFSM/RS, linha de pesquisa Educação e Artes, no ano de 2010, sob orientação da Profa. Dra. Marilda Oliveira de Oliveira.
} 
da viagem, pensando-a como mudança: de cidade, de território, de trânsitos identitários e assim creio que esta mudança pode ser concebida enquanto possibilidade de (re)conhecimento e subjetivação. Aos poucos muitas coisas vão se transformando na pesquisa, algumas são descartadas, outras acrescidas e, foi desta forma que percebi a presença do conceito de deslocamento territorial surgindo no trabalho.

Tal qual o viajante, que se vê envolto pelo ato de arrumar e desarrumar sua bagagem, penso no conceito de desterritorialização proposto por Deleuze e Guattari (1980). E penso nisso posto que ao viajante cabe a tarefa de, antes da partida, organizar sua mala, separando o que lhe é imprescindível: roupas, objetos pessoais, objetos que carrega consigo para ajudar-Ihe a não esquecer de suas referências anteriores, objetos de segurança. Olha para a mala e vai enxergando o que cabe em cada canto, o que pode ir mais ou menos apertado, o que merece maior espaço para acomodar-se. E é somente em razão da saída do território, da viagem, que o ato de arrumar a mala se dá. Assim, a partir deste movimento de saída e no decurso dos trânsitos o viajante vai realocando os pertences trazidos consigo. Contudo, na medida em que vai conhecendo novas paisagens, vivenciando outras situações, passa também a adquirir coisas novas e, então, não basta mais realocar e reordenar o que está contido na mala. Para apropriar-se de coisas novas é necessário, inevitavelmente, desfazer-se de certos objetos, repensar sua urgência ou relevância, como condição de comportar as coisas atuais das quais quer tomar posse.

Retomando o conceito de Deleuze e Guattari, trago-o novamente para ampliar esta escrita. Conforme o filósofo, para haver uma desterritorialização é necessário que haja antes um território, com fronteiras demarcadas, pois que "território são as propriedades (...) e sair do território é se aventurar. O território só vale em relação a um movimento do qual se sai dele" (DELEUZE, 1988: 04).

Deste modo, o movimento de desterritorializar-se só acontece mediante a saída de um território (não necessariamente físico, geográfico. O território pode ser algo subjetivo, outra pessoa, um acontecimento, um pensamento, outros domínios...) num esforço de se reterritorializar em outra parte. Ou seja, é pelo desejo de saída, de descoberta, de busca por outras referências que nos dispomos a encontrar coisas novas: pessoas, lugares, culturas, afetos, conceitos.

É necessário, todavia, esvaziar-se de sentidos e vivências anteriores, no intuito de encharcar-se por novas experiências. Porém, não há com isso necessariamente uma perda de referenciais, mas um movimento de reelaboração, de novos agenciamentos ${ }^{4}$, de diferentes arranjos para dialogar com o que já foi apreendido e o que está em devir. Deste modo, creio que a analogia realizada a partir da experiência vivenciada pelo viajante pode ajudar-nos a compreender este processo de esvaziar-se, dilacerar-se subjetivamente, para que haja este processo de reterritorialização.

No intuito de estabelecer conexões com a noção de deslocamento trago algumas concepções sobre o processo de pesquisa etnográfica, que se constitui invariavelmente por meio da saída por parte do antropólogo, de um território comum, por ele já conhecido e habitado, para um contexto desconhecido, ou, no mínimo pouco familiar aos seus sentidos, ao qual dedica-se ampla e cuidadosamente a observar e explorar por meio de sua inserção.

Em sua vertente clássica, a etnografia tinha como princípios fundamentais a exploração de um território raro, exótico aos olhos do antropólogo, que por sua vez trazia à tona, por meio do trabalho de campo e dos relatos de suas observações, aspectos nunca antes revelados sobre lugares e culturas tão 'misteriosos'. Contudo, é especialmente após o trabalho de campo realizado por Malinowski, em sua longa permanência na Nova Guiné, que o deslocamento e inserção do pesquisador no contexto observado ganha destaque. O autor Vagner Gonçalves da Silva, problematizando a significativa obra de Malinowski, "Argonautas do Pacífico", comenta a importância da observação participante inferindo:

\section{Afinal, como negar a eficácia desse método} quando se lê essa obra e muitas outras que

\footnotetext{
${ }^{4}$ Nesta escrita o conceito de agenciamento é tomado tal qual o proposto por Deleuze e Guattari e por sua vez muito bem explicitado por Tomaz Tadeu da Silva (2000: 15) em seu vocabulário crítico, ou seja, agenciamento seria o termo "utilizado para significar qualquer combinação ou ligação díspare - sem qualquer hierarquia ou organização centralizada - de elementos, fragmentos ou fluxos das mais variadas e diferentes naturezas: ideias, enunciados, coisas, pessoas, corpos, instituições".
} 
Ihe seguiram os passos, nas quais nativos supostamente "exóticos" e distantes são transformados em pessoas próximas, comuns (...), diferentes de nós apenas porque preferem construir canoas sagradas que "voam" sobre as águas em vez de frequentar igrejas com anjos pintados no teto? (2005: 138.)

Com isso, Silva traz-nos uma perspectiva acerca do papel do antropólogo como alguém que, inserido num contexto tão diferente do seu, observa cuidadosamente, faz seus registros e apontamentos, contudo com uma postura menos especulativa sobre o outro, o 'diferente'. Porém, é ainda vinculada à Malinowski outra produção bastante importante e conhecida nas Ciências Sociais: a publicação póstuma de seu diário de campo "Um diário no sentido estrito do termo", em 1967. Ou seja, um material 'não autorizado', que continha detalhes não somente sobre o contexto estudado por ele, mas escritas sobre sua condição de observador participante, incluindo descrições muito particulares acerca de seu estado de espírito, embates e dilemas enquanto inserido na Nova Guiné.

O 'Diário', ao contrário da obra referência Argonautas do Pacífico, que pretendia-se um relato mais 'limpo' e pouco auto-referente, trouxe à tona o lugar do pesquisador, como um negociador, uma pessoa que não torna-se neutra por adentrar um território alheio, mas, ao contrário, lança mão de diferentes estratégias para obter as informações que considera pertinentes ao seu projeto. Assim, acredita-se que a publicação do 'Diário' tenha ainda trazido um novo ponto a ser discutido: a complexidade das relações estabelecidas entre pesquisador e pesquisado, e que até então ficavam excluídas dos textos, teses, livros e relatórios dos antropólogos (SILVA, 2005).

Sendo assim, os conflitos, embates, idiossincrasias e demais aspectos próprios do pesquisador, e do processo de pesquisa, que até então eram relegados aos bastidores da produção acadêmica, ganham visibilidade na medida em que passam a ser percebidos enquanto materiais importantes e influentes para compreender os meandros e particularidades da investigação. Em consequência disto, passam a atuar enquanto possibilidade de conceder espaço ao pes- quisador que sente, tem preferências, crenças, gostos e que carrega consigo visões de mundo que não se separam no momento em que este entra em campo. Deste modo

o mito do pesquisador 'fantasma'(destituído de classe, sexo, cor, opiniões, etc.), que não afeta e não é afetado pelo cotidiano que compartilha com seus interlocutores, ou ainda como um herói da simpatia e da paciência, cuja missão é 'humanizar' o outro, esquecendo-se de que ele também deve ser 'humanizado' em suas fraquezas e omissões, parece agora exigir novas versões (...) Afinal de contas, 'nativos de carne e osso' exigem 'antropólogos de carne e osso', pois é nessa condição que ambos se aproximam e fazem aproximar as culturas ou os valores dos quais são representantes no diálogo etnográfico que estabelecem. (SILVA, 2005: 140)

O antropólogo, por mais inserido que esteja, imerso em rituais e costumes de determinados grupos jamais virá a ser o nativo, e vice-versa, mesmo que ambos vivenciem aspectos pertencentes às diferentes culturas. O antropólogo sempre trará suas cartografias anteriores. Não obstante, creio que encontre-se neste atrito, uma das maiores riquezas das pesquisas em Ciências Humanas: a possibilidade de diálogo com o desconhecido, com aquilo/aquele que não sou. Esta conversação, passível de ser estabelecida entre pesquisadores e demais sujeitos, colaboradores diretos ou indiretos da investigação, compõe um momento profícuo de escuta, conhecimento do outro e de si, na medida em que exercito e experencio a alteridade.

\section{ADENTRANDO AS PÁGINAS DE UM DIÁRIO DE PESQUISA}

Retomando então o diário de campo do pesquisador como importante elemento para pensar os processos investigativos, ou ainda, como lugar onde se inscrevem aspectos que podem servir ao pesquisador durante o período de análise dos dados levantados, trago para o texto uma problematização em torno à minha experiência de pesquisadora, tomando meu diário de pesquisa como objeto a ser explorado. 
Posto isso, tal proposição desenvolve-se enquanto possibilidade de refletir sobre os escritos presentes em meu caderno, usado como espaço destinado ao registro das aulas, seminários e demais acontecimentos desde minha chegada à cidade de Goiânia, no início do ano de 2011, em virtude do doutorado em Arte e Cultura Visual. Nele percebo a chance de melhor compreender as reflexões sobre o tema do deslocamento territorial, bem como perceber a relevância da escrita do pesquisador, como meio de fornecer conteúdos e indícios pertinentes no tocante ao tema investigado.

Quando iniciei o Doutorado estabeleci que, por questões de organização, manteria todas as anotações e escritos de aulas em um mesmo local, independentemente de provirem de disciplinas distintas. Assim, além de reflexões referentes às disciplinas, seria ali também que acrescentaria elementos relacionados à pesquisa. No decorrer deste processo o caderno passou a fazer as vezes de um diário, onde registrava não só partes importantes das aulas e fragmentos das leituras realizadas, como também dei início à inserção de comentários pessoais acerca dos dias que se passavam na nova cidade, sobre minhas percepções diante de determinados fatos, sobre embates vivenciados tanto no contexto da investigação, quanto da própria adaptação ao novo território. Ainda, o diário passou a ser acrescido também por colagens, imagens e referências de diferentes ordens (musicais, fragmentos literários...) e que dialogavam com as reflexões incluídas nas páginas.

Penso que as imagens que agrego no diário de pesquisa me ajudam a entender melhor as mudanças pelas quais venho passando, mudanças que não dizem respeito apenas à nova cidade em que vivo, mas a todo um modo de organização de pensamento, linguagem e de visões de mundo, que paulatinamente se modificam conforme novas relações (pessoais, profissionais, imagéticas) vão se estabelecendo.

Os escritos e colagens inseridos no caderno são escolhidos cuidadosamente e partem da ideia de compor um novo mapa, tendo como referência o que me fora significativo desde que iniciei o curso de doutorado: lugares (novos ou já conhecidos), passeios, sabores, ideias, conhecimentos e pessoas que permearam os novos acontecimentos vivenciados, dando outros sentidos à minha permanência na atual cidade. Para Martins (2010: 22-23) no

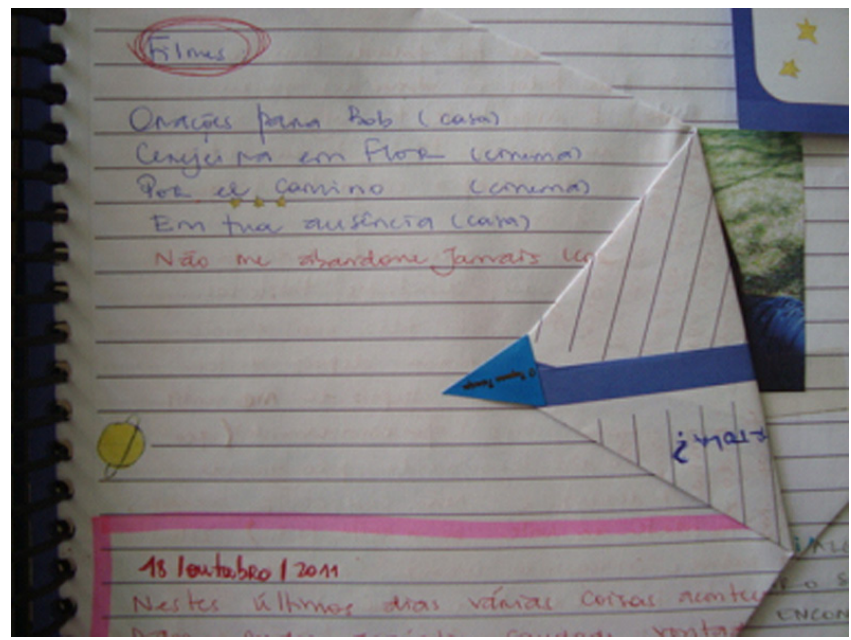

Imagem 2: detalhes do diário

processo de interpretação, ao tentar compreender o sentido simbólico das imagens, os indivíduos são influenciados pelo imaginário dos lugares sociais por onde passam, vivem ou habitam. O território visual onde as pessoas estão situadas - moram, freqüentam, etc. -, ou seja, o contexto das esferas das suas relações com o mundo as coloca num processo de construção de sentidos e significados, de práticas de interpretação.

Assim o local, o lugar em que nos situamos exerce influência direta naquilo que produzimos: projetos de vida, imagens, objetos, artefatos, ao passo que assinalamos (e somos assinalados por) crenças, gostos e modos de ser e pensar. $E$ deste modo acredito que por meio desta imersão e observação do contexto onde me encontro, através dos registros em meu caderno-diário, fui aos poucos percebendo outras possibilidades de entender o processo de pensar a pesquisa e também os modos de ser na docência, na medida em que ampliei meus diálogos com outras experiências. Partilho ainda das ideias de Brea (2010) ao reportar-se à construção do conhecer, que se dá de modo relacional e compartido, fazendo-se num "ruído radial que es la conversacion, lo dialógico, el hacerse únicamente en el intrincado escenário de un venir a ser siempre como un outro- del outro" (p.97). 


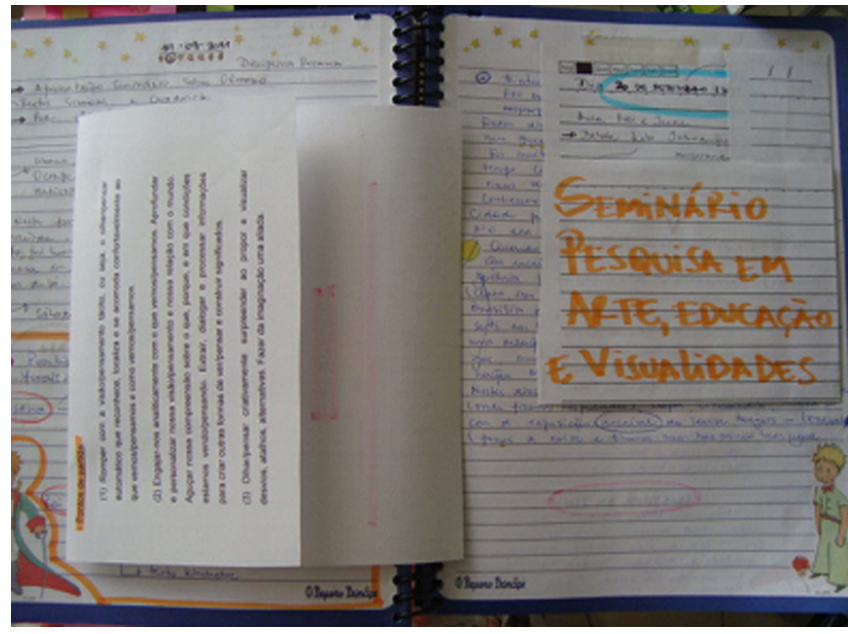

Imagem 3: relações com as aulas de doutorado

A prática de escrita no diário, construída quase diariamente, faz com que observe mais atentamente os fatos que acontecem ao meu redor: no contexto acadêmico, durante as aulas; quando vou a lugares fora do âmbito universitário, como o cinema, por exemplo, em que normalmente faço apontamentos sobre o filme visto e sobre como fui afetada por sua narrativa; quando encontro-me com amigos; nas sessões de orientação da pesquisa doutoral, em que minha orientadora e eu trocamos ideias sobre questões que vão além do projeto, mas que em grande medida ajudam-me a pensá-lo. Promover esta escrita permite um retorno a certos acontecimentos, e ao fazê-lo é possível perceber aspectos citados, que por vezes mostram-se recorrentes.

Eckert e Rocha (2008) apontam um importante dado a respeito da pertinência da escrita realizada pelos antropólogos, inferindo que os diários de campo tratam-se de

Anotações diárias do que o(a) antropólogo(a) vê e ouve entre as pessoas com que ele compartilha um certo tempo de sua vida cotidiana. Os diários de campo, entretanto, não servem apenas como um instrumento de 'passar a limpo' todas as situações, fatos $e$ acontecimentos vividos durante o tempo de um dia compartilhado (...) Ele é o espaço fundamental para o(a) antropólogo(a) arranjar o encadeamento de suas ações futuras em campo, desde uma avaliação de incorreções e imperfeições ocorridas no seu dia de trabalho de campo, dúvidas conceituais e de procedimento ético. (p.15)
Voltar à escrita, para encontrar estes encadeamentos ou buscar pontos mencionados que podem ser relevantes torna-se então uma estratégia importante para encontrar temas de interesse para a investigação, especialmente pois esta escrita serve-me como uma cartografia, que demarca os percursos pensados e vivenciados no cotidiano. Não obstante, é através do retorno ao que foi escrito e agregado ao diário, que realizo as conexões e relações que se fazem efetivamente importantes enquanto pesquisa.

Foi neste ir e vir nas páginas do diário, por exemplo, que percebi a preponderância de aspectos concernentes ao meu deslocamento territorial (respectivo à mudança de santa Maria, no estado do Rio Grande do Sul, para Goiânia, no estado de Goiás). Seja pelas repetidas vezes em que esta questão aparecia em alguns relatos pessoais, seja pelas imagens acrescidas ou pelos fragmentos literários e/ou musicais espalhados nas páginas. Ao reencontrar-me com o que fora escrito até então, percebi que o que mais mobilizava e movimentava meus interesses investigativos era pensar sobre este deslocamento, pensar nos agenciamentos produzidos por esta condição de estar em trânsito, pensando sobre a pertinência disto tudo em minha formação enquanto pesquisadora e professora.

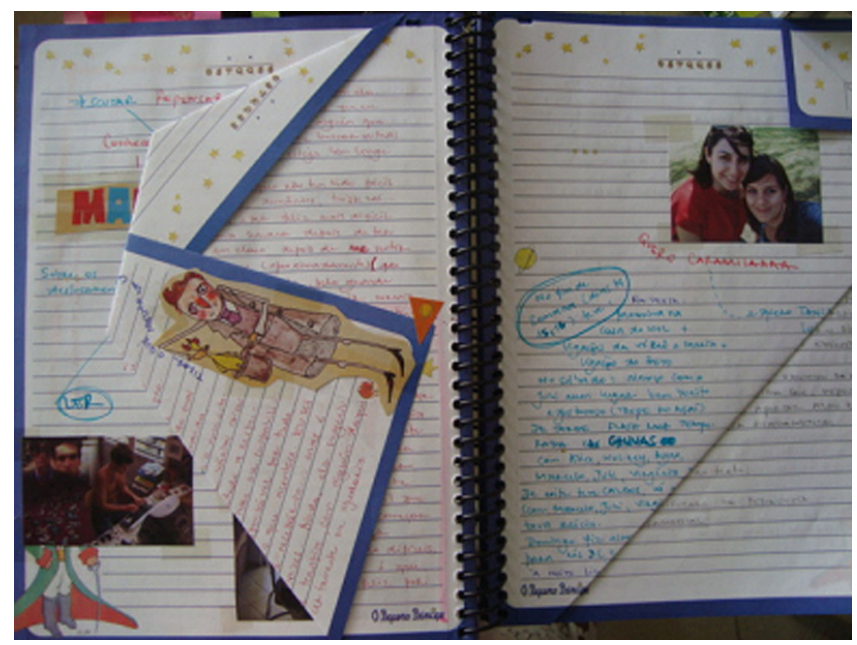

Imagem 4: colagens e dobras do diário

Cartografar estes processos, por meio do ato de escrita cultivado no diário de pesquisa faz-se, portanto como uma possibilidade de perceber quais são as novas paisagens (físicas e conceituais) vistas, pelas quais sou provocada, atraída, domesticada e, sobretudo, desestabilizada. Esta escrita 
parece-me então uma importante estratégia na busca por entender como vou me tornando a pessoa que sou, como possibilidade inclusive de criar espaços de resistência, de reelaboração, na medida em que me reterritorializo em outras partes. Neste sentido, os registros do caderno servem como uma espécie de mapeamento, que apontam os caminhos por onde tenho passado, os trajetos visuais que tenho percorrido. Contém as marcações daquilo que me é caro e intransferível, do que me constituiu de maneira pessoal, mas irrevogavelmente contextual. Apresenta os conflitos vivenciados no contexto da investigação, apontando a necessidade de aprofundar e demorar-se mais com relação à elaboração de questões de pesquisa, articulações conceituais, revisões de posição frente aos conteúdos e autores estudados. Demanda imersão num território que não é físico, mas sim conceitual.

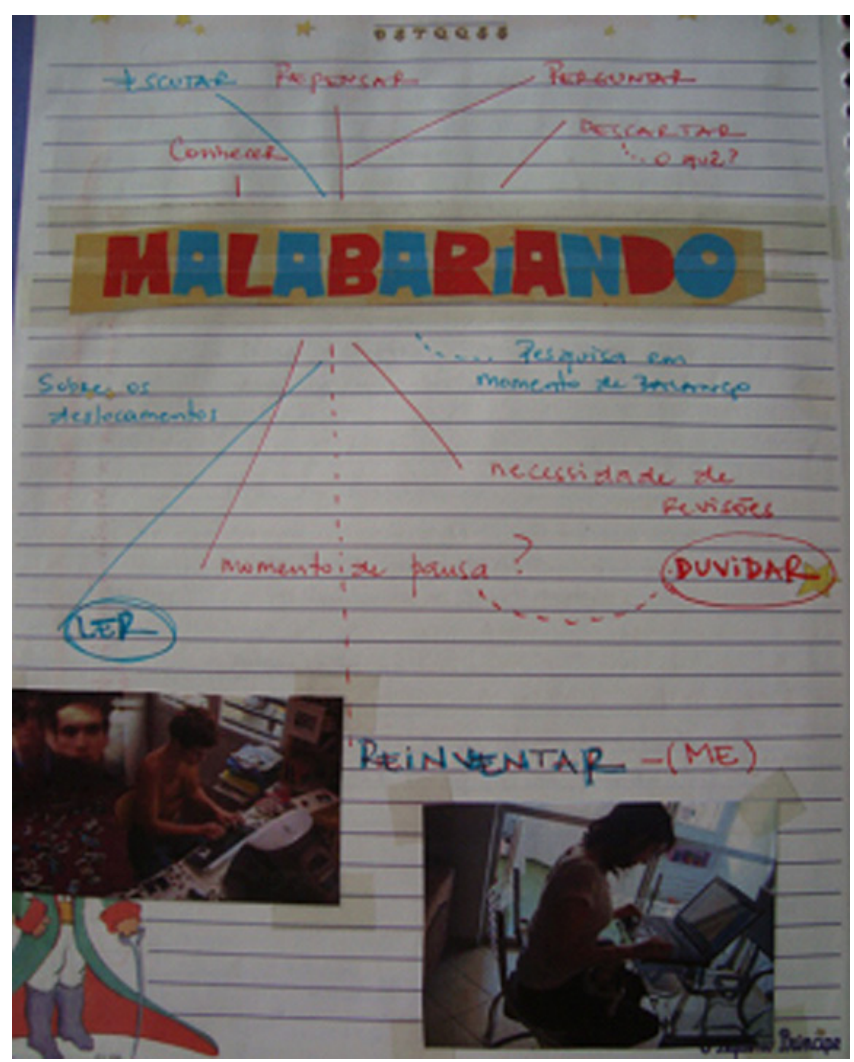

Imagem 5: mapeamento de questões para a pesquisa

Ao pensar no deslocamento, estabeleço uma articulação entre minha condição, de pesquisadora que sai de seu território para estudar em outro lugar, à condição do antropólogo, que desloca-se de seu território em busca do conheci- mento de outras culturas. Para tanto, reporto-me à questão apontada por Eckert e Rocha (por sua vez atribuída ao antropólogo Roberto da Matta) sobre o "sentimento de estar lá e estar aqui como parte das tristezas do antropólogo, um eterno desgarrado de sua própria cultura, mas na eterna busca do seu encontro com outras culturas" (2008: 03).

Portanto, interessa-me pensar nas produções subjetivas que se constroem a partir dos eventos visuais ${ }^{5} \mathrm{com}$ os quais me relaciono, dos processos de revisão que emergem de estar em trânsito, ou do próprio ato de desgarrar-se de um território. O que isto pode trazer para o campo da arte e da cultura visual, enquanto territórios em que me situo? A princípio penso que mais do que trazer respostas, fixar certezas, o trabalho em questão lança possibilidades de produzir sentidos a partir da experiência de migrar de um lugar, de um contexto específico para outro. Sobretudo por pensar que não se trata apenas de um deslocamento entre cidades, mas sim, trata-se de um deslocamento de tudo aquilo que fora considerado domínio anteriormente. Tudo é colocado em dúvida, tudo é repensado e visto desde novas perspectivas.

As articulações produzidas com as imagens trazidas no diário de campo e na pesquisa como um todo, também atuam como narrativas visuais, favorecendo neste caso o que Rifà (2010) comenta sobre

La relación entre autobiografia y visualidad, puede ser productiva para la investigación y la formación del profesorado, ya que crea un espacio abierto para la experimentación y el ensayo. En síntesis, la escritura de relatos visuales autobiográficos posibilita la inscripción de la identidad y la diferencia en la educación artística, lo que modifica los procesos de investigación y desarrollo del currículum, mientras exploramos las oportunidades que nos proporcionan la representación, la crítica, la reflexividad y el diálogo. (p.46)

\footnotetext{
5 Conforme Illeris e Averdsen (2011), o conceito de evento visual inclui toda a situação de observação tal como ocorre na interação entre o observador, o fenômeno visual, o contexto de observação e o ato de olhar propriamente dito. Eventos visuais são sempre situados geográfica, histórica, social e culturalmente, implicando certa interação ou posicionamento entre o observador, o fenômeno observado, o contexto e o olhar.
} 
Neste sentido, ao pensar em relatos ou em narrativas, não restrinjo estas construções à oralidade ou mesmo à produção escrita, sobretudo por considerar que a imagem pode atuar enquanto caminhos para compreendermos de outros modos as contaminações, agenciamentos e subjetivações que se dão nas experiências vividas entorno ao tema dos deslocamentos territoriais, os quais por outro lado talvez não fossem suscitados ou problematizados sem o contato com as visualidades.

Destarte, tomada pelo enfoque em questão, estas referências vão tornando-se afetivas, uma vez que dou-lhes importância e que estabeleço relações de pertencimento ou de distanciamento. As cidades e suas imagens deixam de ser espaços, para tornarem-se lugares, habitados e subjetivados. E assim essa mobilidade permite-me articulações até então impensadas, promovendo outros modos de posicionar-me e produzir no contexto acadêmico.

\section{CONSIDERAÇÕES FINAIS... OU FECHANDO O DIÁRIO POR ORA}

Conforme fora dito ao longo do artigo, cultivar um diário de pesquisa ajuda-me a refletir sobre os percursos, encontros e desencontros que demarcam o processo de pesquisar. São inúmeros os conflitos que se interpõem neste momento de imersão em um novo território e, por isso mesmo, a manutenção de uma escrita autoral, via diário é condição fundamental para conferir visibilidade a movimentos subjetivos, que podem ser pensados em termos da investigação doutoral. Oliveira (2011: 184) ajuda-me a entender este movimento ao dizer que

Toda a escrita é fendida, dobrada, ou seja, selecionamos o que vamos escrever, recortamos o que nos interessa. Silenciamos algumas passagens, potencializamos outras. No momento da escrita travamos uma conversa com o nosso interior, permitimo-nos apagar algumas passagens, acrescentar outras (...)

Neste momento, percebo que as passagens mais recorrentes em meu diário são questões tematizadas e problematizadas em aula, acerca da produção de pesquisas em âmbito acadêmico, bem como no tocante ao campo em ascensão da cultura visual. Aspectos que dizem respeito às minhas inquietudes de jovem pesquisadora e que tem me levado a buscar outras possibilidades de fazer pesquisa, do mesmo modo que fui levada a buscar outros lugares de aprendizagem.

Os apontamentos trazidos demarcam os territórios imagéticos, pessoais, teóricos e conceituais pelos quais tenho transitado, demonstrando que todos estes pontos estabelecem conexões entre si. Ou seja, é difícil separar com precisão o que diz respeito ao âmbito acadêmico, às questões vivenciadas cotidianamente, as relações pessoais. Todas estão mutuamente imbricadas e as inserções do diário deflagram tais entrecruzamentos. E neste viés, penso que a escrita deste diário de pesquisa no decorrer do ano que passou se assemelhe, em certos aspectos, à escrita do diário por parte do antropólogo, que adentra um novo território e/ou uma nova cultura, em busca de novos atravessamentos. Em alguma medida, creio ter realizado uma espécie de etnografia, que buscou observar e refletir sobre os acontecimentos de um contexto muito específico: a cidade de Goiânia, mais especificamente entre as dependências da Faculdade de Artes Visuais, onde realizei minha inserção como pesquisadora e estudante de doutorado; e minha nova casa, local que fui paulatinamente organizando, preenchendo e (re)elaborando conforme minha necessidade de estar e sentir-me em casa, apropriando-me deste local.

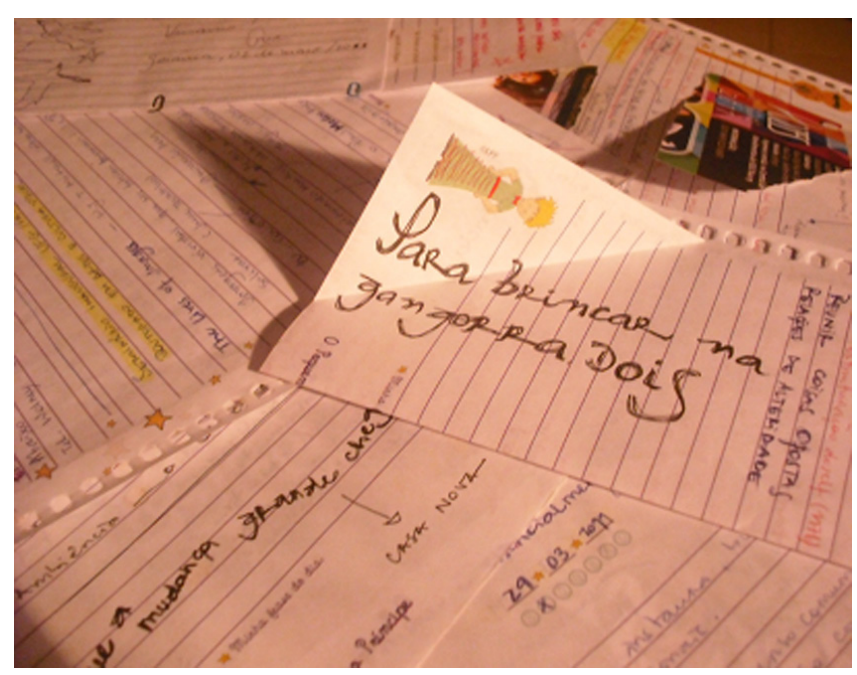

Imagem 6: detalhes das páginas do diário

Não obstante, as anotações realizadas não pretendem falar de modo linear sobre o que vi, mas sim, objetivaram narrar 
partes de momentos e situações vivenciadas nestes locais mencionados. Aspectos ouvidos nas aulas, comentários de colegas e professores, relatos acerca dos dias que se passaram.

Levando em consideração as palavras de Clifford, ao refletir que "en la etnografía no hay verdades absolutos sino parciales, incompletas"(1991: 34), ou seja, tudo o que fora escrito e incluído no diário foi pensado enquanto possibilidade de registrar e melhor compreender a experiência vivida, desde minha perspectiva e meu lugar de fala. Falo, portanto desde relações muito particulares, de um olhar que se volta para tentar compreender uma dinâmica nova, na qual inserem-se pessoas, costumes, modos de ver e explicar o mundo, em grande parte diferentes daquilo que fora vivenciado anteriormente.

Particularmente, considero que tais questões só ganham interesse investigativo uma vez que podem ser partilhadas e debatidas em termos dos agenciamentos promovidos no campo da formação docente, da cultura visual e das artes visuais, ou ainda no contexto das reflexões metodológicas aportadas na pesquisa, como forma de evocar novas narrativas a partir de experiências vividas. Estas, ao serem compartilhadas podem operar enquanto convites a novas reflexões e produções advindas de outros pares. Tais experienciações poderiam ser pensadas como dispositivos que acionam produções e compartilhamentos de conhecimentos e saberes, de modo relacional.

Ao promover uma conversação entre os escritos e imagens contidas no diário e a prática da escrita etnográficas, mais precisamente os diários produzidos pelos antropólogos em suas idas à campo, o texto em questão trouxe-me a possibilidade de refletir a respeito da relevância deste tipo de escrita para o âmbito das pesquisas acadêmicas. Mais ainda, proporcionou uma imersão ao material contido em meu diário de campo, conferindo tempo e subsídios teóricos para compreender sua pertinência na pesquisa doutoral. Posto isso, creio que, a partir dos aspectos levantados até então, o trabalho que desenvolvo articula-se às características da pesquisa narrativa uma vez que esta

não discute apenas questões ontológicas, ou seja, características existenciais comuns aos seres humanos como narradores. Principalmente, a pesquisa narrativa se debruça sobre questões epistemológicas que possam ajudar a compreender e explicar como práticas cul- turais, sociais e visuais marcam a trajetória e a subjetividade dos indivíduos, seus modos de perceber, interpretar e narrar. Preocupa-se, ainda, com a compreensão de como essas práticas configuram ideias, conceitos e representações. (MARTINS e TOURINHO, 2009: 1-2)

Sendo assim, prossigo em busca de ampliar meus repertórios no que concerne à perspectiva narrativa, por entendê-la como um meio relevante para investigar a partir e sobre o que podemos aprender de nós mesmos, em relações que acionam memórias sobre experiências vividas, que permanecem reverberando afetos e sentidos, em experiências que promovem mudanças e acrescentam possibilidades de ser e entender a profissão docente ou o próprio processo de pesquisar.

\section{REFERÊNCIAS}

BREA, José Luis. (2010) Las Tres Eras de la Imagen - imagen-materia, film, e-image. Madrid: Akal.

CLIFFORD, James. (1991) Introduccion: verdades parciales. In Clifford, James and Marcus, George E. Retóricas de la Antropologia (25-60) Madri, Júcar.

DELEUZE, Gilles. (1988) O abecedário de Gilles Deleuze: transcrição integral do vídeo, para fins exclusivamente didáticos. Éditions Montparnasse: Paris.

ECKERT, Cornelia; ROCHA, Ana Luiza Carvalho da. Etnografia: saberes e Práticas. (2008) Revista Iluminuras - Publicação eletrônica do Banco de Imagens e Efeitos Visuais, v. 9, n. 21.

ILLERIS, Helene; AVERDSEN, Karsten. Fenômenos e eventos visuais: algumas reflexões sobre currículo e pedagogia da cultura visual. 2011, no prelo.

MARTINS, Raimundo. Pensando com imagens para compreender criticamente a experiência visual. In: Assis, Henrique Lima; Rodrigues, Edvânia Braz Teixeira. Educação das Artes Visuais na Perspectiva da Cultura Visual: Conceituações, Problematizações e Experiências. (19-38) Goiânia: 2010.

MARTINS, Raimundo; TOURINHO, Irene (2009). Pesquisa narrativa: concepções, práticas e indagações. (DVD) In: Anais do /l Congresso de Educação, Arte e Cultura-CEAC. 1-12. Santa Maria: setembro 2009.

OLIVEIRA, Marilda Oliveira de. (2011) Por uma abordagem autobiográfica: diários de aula como foco de investigação. In: MARTINS, Raimundo e TOURINHO, Irene (Orgs), Educação da Cultura Visual - conceitos e contextos. (175-190) Santa Maria: Editora da Universidade Federal de Santa Maria.

RIFÀ, Montserrat.(2010) Narrativas autobiográficas en la investigación educativa basada en las artes y en el currículum de formación del profesorado. In: EÇA, Teresa Torres Pereira de; PARDIÑAS, Maria Jesus Agra; MARTíNEZ, Cristina Trigo e PIMENTEL, Lúcia Gouvêa (Orgs.). Desafios da educação Artística Ibero-America. (36-48) Porto, Portugal: APECV (Associação de Professores de Expressão e Comunicação Visual).

SILVA, Tomaz Tadeu da. (2000) Teoria cultural e educação - um vocabulário crítico. Belo Horizonte: Editora Autêntica.

SILVA, Vagner Gonçalves da.(2005) Entre a poesia e o raio X: uma introdução à tendência pós-moderna na antropologia. In: Guinsburg, J. e Barbosa, Ana Mae (orgs.), Pós-modernismo. (145-158) São Paulo: Perspectiva. 